Original Article :Article type

\title{
In vitro biofilms and antifungal susceptibility of dermatophyte and non-dermatophyte molds involved in foot mycosis
}

\section{Nourchéne Toukabri ${ }^{1}$, Serena Corpologno ${ }^{2}$, Marie-Elisabeth Bougnoux ${ }^{3}$, Dalenda El Euch ${ }^{4}$, Najla Sadfi-Zouaoui ${ }^{1}$ and Giovanna Simonetti ${ }^{2 *}$}

${ }^{1}$ Laboratory of Mycology, Pathologies and Biomarkers, Faculty of Sciences of Tunis, University Tunis El Manar 2092 Tunis, Tunisia

2 Department of Public Health and Infectious Diseases, "Sapienza" University of Rome, Rome, Italy

3 Department of Microbiology, Hôpital Necker-Enfants Malades AP-HP, University ParisDescartes, Paris, France.

${ }^{4}$ Department of Dermatology and Venereology, Hôpital La Rabta, Tunis, Tunisia.

Running head: foot mycosis: biofilm and drug sensitivity

Key words: Tinea pedis, onychomycosis, dermatophytes, fungal biofilm, susceptibility tests.

* Corresponding author:

Giovanna SIMONETTI

This article has been accepted for publication and undergone full peer review but has not been through the copyediting, typesetting, pagination and proofreading process, which may lead to differences between this version and the Version of Record. Please cite this article as doi: 10.1111/myc. 12706

This article is protected by copyright. All rights reserved. 
Department of Public Health and Infectious Diseases "Sapienza", University of Rome, Piazzale Aldo Moro 5, 00185, Rome, Italy.

Phone/Fax number: (+39) 064468626/ (+39) 064468625

E-mail: giovanna.simonetti@uniroma1.it

\section{Summary}

Background: Tinea pedis and onychomycosis are among the commonest fungal diseases in the world. Dermatophytes and, less frequently, non-dermatophyte molds are etiological agents of foot mycosis and could be able to form biofilms. Fungal biofilm has demonstrated increasing drug resistance Objectives: This work aims to evaluate in vitro the ability to form biofilm and the susceptibility to antifungal drugs of sessile dermatophytes and non-dermatophyte molds involved in foot mycosis. Methods: Thirty-six dermatophytes and non-dermatophyte molds isolated from Tunisian patients with foot mycoses, and identified with MALDI-TOF have been tested. MICs of fluconazole, econazole, itraconazole, terbinafine and griseofulvin were carried out using CLSI broth microdilution method. The ability to form biofilm and antifungal activities of drugs against fungal biofilm formation has been quantified by Crystal Violet and Safranin Red staining. Results: Biomass quantification revealed that all species studied were able to form biofilms in vitro after $72 \mathrm{~h}$. Fluconazole, econazole, itraconazole and terbinafine inhibited fungal growth with MIC values ranging from 0.031 to $>64 \mu \mathrm{g} \mathrm{ml}^{-1}$. The best antifungal activity has been obtained with terbinafine against Fusarium solani. Econazole showed the highest activity against fungal biofilm formation. Conclusion: These findings can help clinicians to develop the appropriate therapy of foot mycosis.

\section{Introduction}

Tinea pedis and onychomycosis are among the commonest fungal diseases in the world; these affect the elderly, children and adults ${ }^{1-3}$. The most frequently identified fungi are dermatophytes. Trichophyton rubrum is the most common specie but various non-dermatophyte molds (NDMs) are also isolated from diseased nails such as Scopulariopsis brevicaulis, Fusarium spp., Aspergillus spp. ${ }^{4-6}$. Among the known Aspergillus spp., A. versicolor and A. sydowii are the species most commonly associated to foot infections, including onychomycosis, other species like A. candidus, A. fumigatus, A. niger, A. flavus, A. terreus, A. ochraceus and A. sclerotiorum 
are also incriminated ${ }^{7,8}$. Fusarium solani and Fusarium oxysporum are etiological agents of onychomycosis caused by Fusarium species ${ }^{9}$.

These infections are considered as an important public health problem, constituting a large bulk of cases attending the dermatology departments and this can be due to the high prevalence, longterm therapy and difficult eradication of recurrent chronic nails infection ${ }^{10-12}$.

The treatment of foot mycosis can be local but essential systemic treatment is required depending to the type and location of lesions. Currently the treatment of dermatophyte infections is usually long term, with several cases of recurrence ${ }^{13}$.

Furthermore, systemic antifungal agents present many disadvantages such as therapeutic limitations with high toxicity, many drugs interactions and resistance ${ }^{14}$. In another hand, the study of antifungal susceptibility mechanism constitutes an important strategy to restrict the emergence of resistance to the commercially available agents and may help to provide the efficacy of an antifungal drug, so that the development of new and potential compounds is necessary ${ }^{15}$.

Dermatophytes and NDMs have the ability to adhere on biotic or abiotic surface forming biofilms 16-18. Fungal biofilm represent an important role in the pathogenesis and in the resistance to the antimicrobial agents ${ }^{18}$. Many methods have been developed to evaluate the quantity of biofilm 19,20. The Cristal violet assay has been demonstrated to be the most reliable test, which stains metabolically active and inactive cells in mature biofilms ${ }^{21}$.

The aims of the present study were to evaluate the in vitro ability to form biofilms and antifungal susceptibility of clinical isolates of dermatophytes and NDMs implicated in foot mycosis. Crystal Violet and Safranin Red staining quantified the amount of biofilm.

\section{Materials and methods}

\section{Fungal strains}

Clinical strains were isolated from patients with foot mycosis attending the Mycology Unit of the dermatology Department in the University Hospital la Rabta (Tunis) until a prospective study enrolled in Tunisia ${ }^{22}$. Thirty six strains were included in this study (Table 1), 26 dermatophyte species including Trichophyton rubrum $(\mathrm{n}=21)$, Trichophyton interdigitale $(\mathrm{n}=5)$, and 10 molds including Scopulariopsis brevicaulis $(\mathrm{n}=3)$, Fusarium solani $(\mathrm{n}=2)$, Fusarium oxysporum $(\mathrm{n}=2)$, Chrysosporium keratinophylum $(\mathrm{n}=2)$ and Aspergillus terreus $(\mathrm{n}=1)$. T. mentagrophytes DSM

This article is protected by copyright. All rights reserved. 
4870 and A. terreus DSM 1958 from German Collection of Microorganisms (DSMZ, Braunschweig, Germany), were used as references strains. Initially, all isolates were identified using standard methods based on macroscopic and microscopic characteristics. Then, identification of fungal strains was confirmed by analysis of protein using MALDI-TOF MS (Parasitology-Mycology Unit in the Department of Microbiology, Necker-Enfants Malades Hospital AP-HP, Paris, France). Isolates were stored at $-80^{\circ} \mathrm{C}$ on Sabouraud Broth (Sigma Aldrich, St. Louis Missouri, USA) with $30 \%$ glycerol until the time of use.

\section{Antifungal susceptibility assay}

The minimal inhibitory concentration (MIC) on planktonic cells was determined using the broth microdilution method according to the Clinical and Laboratory Standards Institute reference for filamentous fungi ${ }^{23}$. All strains were grown on Potato Dextrose Agar (Sigma Aldrich, St. Louis Missouri, USA) at $28-30^{\circ} \mathrm{C}$ until conidia formation. Inoculum suspension was prepared at final concentration of $0.4 \times 10^{4}$ to $5 \times 10^{4} \mathrm{CFU} \mathrm{ml}^{-1}$. The in vitro antifungal activity was evaluated using five antifungal agents: fluconazole (FLC), econazole (ECO) (Sigma Aldrich, St. Louis Missouri, USA), with concentrations ranged from 64 to $0.125 \mu \mathrm{g} \mathrm{ml}^{-1}$ respectively and for itraconazole (ITC), terbinafine (TRB) and griseofulvin (GSF) (Sigma Aldrich, St. Louis Missouri, USA) from 16 to $0.032 \mu \mathrm{g} \mathrm{ml}^{-1}$. $\mathrm{MIC}_{50}$ was defined as the lowest concentration that caused $\geq 50 \%$ growth inhibition; $\mathrm{MIC}_{80}$ was the lowest concentration that caused $80 \%$ growth inhibition and the $\mathrm{MIC}_{100}$ the lowest drug concentration that inhibited $100 \%$ of growth.

\section{Evaluation of biofilm formation}

The biofilm assay was performed with the use of methods described previously ${ }^{19,24}$. All strains were grown on Potato dextrose agar (Sigma Aldrich, St. Louis Missouri, USA), incubated at

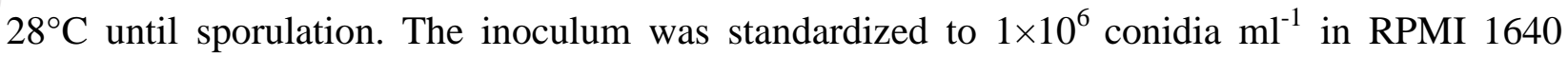
medium supplemented with L-glutamine, buffered with MOPS acid (Sigma-Aldrich), and added to 24 -well plates. After $24-72 \mathrm{~h}$ at $37^{\circ} \mathrm{C}$, the cells were washed two times with sterile saline water $0.9 \%$ for removal of non-adherent cells. Morphology of biofilm was observed by light microscopy.

This article is protected by copyright. All rights reserved. 


\section{Biofilm quantification}

Crystal Violet ${ }^{19,24}$ and Safranin Red ${ }^{25}$ bind to negatively charged molecules and can be used to stain and quantify total biomass comprising fungi and EPS Total Biomass

\section{Cristal violet staining}

After biofilm formation, the plates are dried at room temperature for $10 \mathrm{~min}$ and $1 \mathrm{ml}$ of $0.5 \%$ Crystal Violet solution was added to each well for $30 \mathrm{~min}$. The wells were washed two times with sterile water to remove excess of crystal violet and biofilm were decolorized by the addition of $1 \mathrm{ml}$ of 80:20 ethanol/acetone solutions to each well. This solution was gently homogenized with a pipette until the rest of the crystal violet was completely dissolved ( $1 \mathrm{~min})$. Finally, the solution from each well was transferred to a new 96-well plate and then read in a microplate reader at $570 \mathrm{~nm}$. All experiments were performed in triplicate.

\section{Safranin staining}

After the biofilm formation for $72 \mathrm{~h}$ in 96 -well plates, the plates were washed three times with $200 \mu 1$ of phosphate buffered saline (PBS) (Sigma Aldrich, St. Louis Missouri, USA) and dried at $50^{\circ} \mathrm{C}$ for $30 \mathrm{~min}$. Each well was stained with $50 \mu \mathrm{l}$ of safranin solution $1 \%$ for $5 \mathrm{~min}$, and then washed three times with $200 \mu \mathrm{l}$ of PBS until the supernatant stayed clear. Finally, the optical density OD was read at $492 \mathrm{~nm}$.

\section{Antifungal susceptibility of dermatophyte and NDM biofilms}

All strains were grown on Potato dextrose agar (Sigma Aldrich, St. Louis Missouri, USA), incubated at $28^{\circ} \mathrm{C}$ until sporulation. The inoculum was standardized to $1 \times 10^{6} \mathrm{conidia} \mathrm{ml}^{-1}$ in RPMI 1640 medium supplemented with L-glutamine and buffered with MOPS acid (SigmaAldrich) and was allowed to form biofilm in 96-well polystyrene plates in the presence of five concentrations of ECZ and TER (16, 8, 4, 2 and $\left.1 \mu \mathrm{g} \mathrm{ml}^{-1}\right)$. After incubation, the biofilm was quantified using crystal violet staining as previously described ${ }^{20,23}$. The concentrations causing $50 \%$ inhibition of biofilm formation due to drug treatment have been determinated.

\section{Statistical analysis}

The antifungal activities are the result of three independent experiments performed in duplicate. The data of antifungal activity (MIC) have been presented as median. In order to relate the biofilm content and, the MIC values of the different strains Pearson's correlation coefficient (r)

This article is protected by copyright. All rights reserved. 
have been estimated. The correlation coefficient close to 1 indicates that the variables are positively and linearly related. The zero value indicates weak relationship between the variables, a correlation less than 0.5 is weak.

\section{Results}

The results of antifungal activity $\left(\mathrm{MIC}_{50}, \mathrm{MIC}_{80}\right.$, and $\left.\mathrm{MIC}_{100}\right)$ of FLC, ECO, ITC, TRB and GSF against planktonic cells of dermatophytes (T. rubrum, T. interdigitale) and NDMs (F. solani, F. oxysporum, A. terreus, S. brevicaulis and C. keratinophylum have been reported in Table 2. Fusarium spp., S. brevicaulis and A. terreus were resistant to FLC $\left(\mathrm{MIC}_{50}>64 \mu \mathrm{g} \mathrm{ml}^{-1}\right)$, ITC $\left(\mathrm{MIC}_{50}>16 \mu \mathrm{g} \mathrm{ml}^{-1}\right)$ and GSF $\left(\mathrm{MIC}_{80}>16 \mu \mathrm{g} \mathrm{ml}^{-1}\right)$. The strains of $F$. solani were resistant to all antifungal tested $\left(\mathrm{MIC}_{100}>16 \mu \mathrm{g} \mathrm{ml}^{-1}\right.$ for ITC, TER, GSF and $\mathrm{MIC}_{50}>64 \mu \mathrm{g} \mathrm{ml}^{-1}$ for FLC, ECO). All the Trichophyton spp. strains were susceptible to TRB with $\mathrm{MIC}_{80}$ values of $<0.032 \mu \mathrm{g} \mathrm{ml}^{-1}$. Trichophyton spp, causing tinea pedis showed resistance to $\mathrm{FLC}$ with $\mathrm{MIC}_{80}$ values of $\geq 64 \mu \mathrm{g}$ $\mathrm{ml}^{-1}$.

All the strains demonstrated the ability to form biofilm on 24-well microtitration plate surface, however differences were observed among them (Fig. 1). T. rubrum (T21; T40 and T25) biofilms, T.interdigitale (T1) biofilm, F. oxysporum (M1 and M2) biofilms, S. brevicaulis (M3; M6 and M12) biofilms, C. keratinophylum (T37) biofilm and A. terreus (M5) biofilm produce a high amount of biomass (Fig. 1). In the present study, the species of F. solani (M7, M8) and $S$. brevicaulis (M3, M6) resistant clinical isolates, showed the most capacity to form biofilm on a polystyrene surface.

The results of biomass quantification of all isolates were presented in Figure 1, showed a correlation between Crystal violet (Fig. 1a) and Safranin staining amount ( $r=0.694)$ (Fig 1b).

The amount of mature biofilm was not correlated to antifungal activity against all planktonic cells tested FLC-MIC 80 values $(r=0.4422)$, FLC-MIC $100(\mathrm{r}=0.0584)$, ECO-MIC 80 values $(r=0.2135)$, ITC-MIC $_{80}$ values $(\mathrm{r}=0.3534)$ and $\mathrm{TRB}-\mathrm{MIC}_{80}$ values $(\mathrm{r}=0.1317)$.

The antifungal activity of ECO and TRB against biofilm formation was measured in terms of percentage of inhibition and the results are shown in Figure 2. The effect of antifungal agents against biofilm formation was measured in terms of the percentage of inhibition; the in vitro assay showed that at concentration of $4 \mu \mathrm{g} \mathrm{ml}^{-1}$, the percentage ranged from $0 \%$ to $95 \%$ for ECO

This article is protected by copyright. All rights reserved. 
and from $4 \%$ to $93 \%$ for TRB. The best results were obtained with the ECO when compared with TRB on the strains tested.

However, for Fusarium species (M2 and M8), the in vitro biofilms assay showed a low susceptibility to the tested antifungal agents.

\section{Discussion}

The commonest agents of foot mycosis are dermatophytes such as the anthropophilic T. rubrum ${ }^{26,27}$ also NDMSs like Fusarium spp., S. brevicaulis and Aspergillus sp. can be incriminated but in low rates ${ }^{22,28-30}$. The first step of treatment of tinea pedis and tinea unguium is to make precise diagnosis in order to provide the appropriate antifungal agent. Recently, the therapy of foot mycosis represents a major challenge, frequent failures and recurrent infection are observed ${ }^{31-33}$, inappropriate selection of antifungal agents in addition to inadequate dose and duration of therapy could facilitates the rapid recurrence of infection and also the development of drug resistance. The methods of the in vitro antifungal activity can be useful to predict the capacity of a determined antifungal agent to detect the resistance trends and to eradicate the determined fungal species. To our knowledge, few studies have been conducted in Tunisia focused on the antifungal susceptibility among dermatophytes and NDMs responsible for foot mycosis. Actually, ITC, FLC and TRB are the most widely available antifungal agents used for systemic treatment of onychomycosis. In order to have successful therapy for biofilm onychomycosis, it is necessary to use an antifungal especially for biofilm degradation. Although, many systemic antifungal drugs had also been associated with some adverse side effects such as headache, hepatotoxicity, gastrointestinal disturbance (nausea, diarrhea, vomiting), skin rash and impotency ${ }^{34,35}$ and for this reason it is important that therapy be preceded by drug sensitivity tests .

In this study, low MICs of ECO, ITC, TRB and GSF have been reported. However, FLC had the highest MIC value against all the clinical dermatophyte strains ${ }^{36,37}$. TRB was the most effective antifungal against T.rubrum and T.interdigitale species causing onychomycosis and tinea pedis. Previous studies ${ }^{38-41}$ reported that TRB has a higher clinical cure with a slower relapse rates in a short period of treatment ${ }^{42}$. GSF was the first systemic treatment for skin and nail infections but demonstrate a limited spectrum activity to dermatophytes ${ }^{43,44}$. Moreover, GSF demonstrate a MIC values $>16 \mu \mathrm{g} \mathrm{ml}^{-1}$ against some resistant dermatophyte isolates ${ }^{44,45}$ In addition, we note

This article is protected by copyright. All rights reserved. 
that GSF is less active against T.rubrum and T. interdigitale than the other antifungal agents beyond FLC.

Concerning the derivative azoles, ITC and ECO were demonstrated to be the most active agents against Trichophyton spp. agents of tinea pedis and tinea unguium ${ }^{46,47}$; otherwise, ITC was more effective in tinea pedis than ECO this finding is confirmed by study of Decroix. $1995^{48}$ showing a successful oral treatment of tinea pedis with ITC. However FLC showed a high MIC values $\left(>64 \mu \mathrm{g} \mathrm{ml}^{-1}\right)$ especially for species related to tinea pedis. These differences in the susceptibility can be explained by the fact that derivate azoles target fungal ergosterol in the structure differs among species.

In the present study, also NDMs such as Fusarium spp, S. brevicaulis, and A. terreus and $C$. keratinophylum were isolated from patients with foot mycosis. The treatment of tinea pedis and tinea unguium caused by NDMs is still not well standardized and many authors point out the poor therapeutic response of these fungal infections to systemic antifungal drugs ${ }^{49-52}$. We found that azoles (FLC, ECO, and ITC) and GSF showed a very high MICs values for the strains of $S$. brevicaulis and Fusarium spp. However, TRB presents a low MICs values for the strains of $S$. brevicaulis and $F$. oxysporum. In the other hand, the isolates of $F$. solani are resistant to all the antifungal tested, this can be explained by the characteristics of Fusarium species to be refractory and represents in vivo and in vitro resistance to most antifungal drugs ${ }^{53-56}$.

The capacity of dermatophyte and NDM isolates to form biofilms is generally related to the ability to cause infection. In the present work, we have assessed the biofilm production by dermatophytes and NDMs associated to foot mycosis. Otherwise, a first work has reported the in vitro biofilm forming abilities of T. rubrum and T. mentagrophytes ${ }^{19}$, and many other studies reported the biofilm formation of some filamentous fungi ${ }^{25,57}$. However, to our knowledge, the biofilm production by molds $S$. brevicaulis and $C$. keratinophylum associated to foot mycosis has not been described. Overall, all the isolates had the ability to adhere to the polystyrene surface and form biofilm in different degrees depending on the species. In the present study, the species of F. solani (M7, M8) and S. brevicaulis (M3, M6) resistant clinical isolates, showed the most capacity to form biofilm on a polystyrene surface. These finding let us suppose that the high production of biofilm, that is a permeability barrier surprisingly resistant to injury, could contribute to their survival, act as a persistent source of infection and further dissemination and account for antifungal resistance in onychomycosis ${ }^{58,59}$. The low susceptibility of Fusarium

This article is protected by copyright. All rights reserved. 
biofilm (M2 and M8) to the tested antifungal agents, could confirmed the hypothesis of Seidler et al. ${ }^{25}$.

The maturation of biofilm and the high cell density in the biofilm matrix may influence the different susceptibility to antifungal drugs.

Many factors suggest that biofilm represent an important role in the pathogenesis of onychomycosis including firm adherence of dermatophytes in the nail plate and ability to form biofilm, which increased of virulence and resistance to the antimicrobial agents (Nusbaum et al., 2012).

The differences in anti-biofilm assays, among dermatophyte and NDM species, can be related to the life cycle of biofilm especially in the maturation stage associated to the composition of the biofilm matrix and the rate of the drug diffusion through the biofilm.

Successful treatment of onychomycosis can be explained in first by the biofilm formation and for the susceptibility assay, antifungal agents should be tested among biofilms and not planktonic cells. Biofilm assays performed in vitro could allow for rapid screening of antifungal compounds. Appropriate selection of antifungal agents with adequate dose could help to resolve the infection and reduce its spread. In the recommendations given by ESCMID there is the urgent need to standardized biofilm susceptibility test and to biofilm-specific breakpoints for systemic and topically administered antibiotics 60 .

Therefore, the increased levels of biofilm resistance underline the importance of developing assays to test biofilm antifungal susceptibilities. Such future research in antifungal drugs and their exact mode of action against dermatophyte and NDM biofilms are needed to be developed in order to target sessile cells.

\section{Acknowledgement}

This study has been supported by funds from the Ministry of Higher Education and Scientific Research of Tunisia (LR16ES05) and from "Sapienza" University of Rome (Ricerche (Universitarie C26A15MLP9).

\section{Conflict of Interest}

The authors have declared that there is no conflict of interest.

This article is protected by copyright. All rights reserved. 


\section{References}

1. Gupta AK, Jain HC, Lynde CW, Macdonald P, Cooper EA, Summerbell RC. Prevalence and epidemiology of onychomycosis in patients visiting physicians' offices: a multicenter canadian survey of 15,000 patients. J. Am. Acad. Dermatol. 2000;43:244-248.

2. Gregory N. Special patient populations: onychomycosis in the HIV-positive patient. $J$. Am. Acad. Dermatol. 1996;35(3 Pt 2):S13-16.

3. Perea S, Ramos MJ, Garau M, Gonzalez A, Noriega AR, del Palacio A. Prevalence and risk factors of tinea unguium and tinea pedis in the general population in Spain. J. Clin. Microbiol. 2000;38:3226-3230.

4. Kaur R, Kashyap B, Bhalla P. Onychomycosis--epidemiology, diagnosis and management. Indian J. Med. Microbiol. 2008;26:108-116.

5. Farwa U, Abbasi SA, Mirza IA, et al. Non-dermatophyte moulds as pathogens of onychomycosis. J. Coll. Physicians Surg. Pak. 2011;21(10):597-600.

6. Dhib I, Fathallah A, Yaacoub A, Zemni R, Gaha R, Said MB. Clinical and mycological features of onychomycosis in central Tunisia: a 22 years retrospective study (1986-2007). Mycoses. 2013;56:273-280.

7. Contet-Audonneau N. Les Onyxis À Moisissures. Revue Francophone des Laboratoires. 2005/05/01/ 2005;373:35-44.

8. Negroni R. Onychomycosis Due to Aspergillus Species. In: Comarú Pasqualotto A, ed. Aspergillosis: From Diagnosis to Prevention. Dordrecht: Springer Netherlands; 2010:961-971. 9. Nucci M, Anaissie E. Fusarium infections in immunocompromised patients. Clin. Microbiol. Rev. 2007;20:695-704.

10. Sigurgeirsson B, Steingrimsson O. Risk factors associated with onychomycosis. J. Eur. Acad. Dermatol. Venereol. Jan 2004;18(1):48-51.

11. Elewski BE. The effect of toenail onychomycosis on patient quality of life. Int. J. Dermatol. 1997;36:754-756.

12. van der Schroeff JG, Cirkel PK, Crijns MB, et al. A randomized treatment durationfinding study of terbinafine in onychomycosis. Br. J. Dermatol. Feb 1992;126 Suppl 39:36-39.

13. Kumar P, Latka C, Taneja B. Current Antifungal Therapy and Drug Resistance Mechanisms in Dermatophytes. In: Arora G, Sajid A, Kalia VC, eds. Drug Resistance in Bacteria, Fungi, Malaria, and Cancer. Cham: Springer International Publishing; 2017:371-385.

This article is protected by copyright. All rights reserved. 
14. Alley MRK, Baker SJ, Beutner KR, Plattner J. Recent progress on the topical therapy of onychomycosis. Expert Opinion on Investigational Drugs. 2007/02/01 2007;16(2):157-167.

15. Pfaller MA. Antifungal drug resistance: mechanisms, epidemiology, and consequences for treatment. Am. J. Med. Jan 2012;125(1 Suppl):S3-13.

16. Sutherland IW. The biofilm matrix--an immobilized but dynamic microbial environment. Trends Microbiol. May 2001;9(5):222-227.

17. Reynolds TB, Fink GR. Bakers' yeast, a model for fungal biofilm formation. Science. Feb 2 2001;291(5505):878-881.

18. Nusbaum AG, Kirsner RS, Charles CA. Biofilms in dermatology. Skin Therapy Lett. Jul 2012;17(7):1-5.

19. Costa-Orlandi CB, Sardi JC, Santos CT, Fusco-Almeida AM, Mendes-Giannini MJ. In vitro characterization of Trichophyton rubrum and T. mentagrophytes biofilms. Biofouling. 2014;30(6):719-727.

20. Melo AS, Bizerra FC, Freymuller E, Arthington-Skaggs BA, Colombo AL. Biofilm production and evaluation of antifungal susceptibility amongst clinical Candida spp. isolates, including strains of the Candida parapsilosis complex. Med. Mycol. Apr 2011;49(3):253-262.

21. Jin Y, Yip HK, Samaranayake YH, Yau JY, Samaranayake LP. Biofilm-forming ability of Candida albicans is unlikely to contribute to high levels of oral yeast carriage in cases of human immunodeficiency virus infection. J. Clin. Microbiol. Jul 2003;41(7):2961-2967.

22. Toukabri N, Dhieb C, El Euch D, Rouissi M, Mokni M, Sadfi-Zouaoui N. Prevalence, Etiology, and Risk Factors of Tinea Pedis and Tinea Unguium in Tunisia. Canadian Journal of Infectious Diseases and Medical Microbiology. 2017;2017:9.

23. Rex J.H. ABD, Andes D., Arthington-Skaggs B., Brown, S.D. CV, Espinel-Ingroff A., Ghannoum M.A., Knapp, C.C. MMR, Ostrosky-Zeichner L., Pfaller M., Sheehan D.J.,, T.J. W. Reference Method for Broth Dilution Antifungal Susceptibility Testing of Filamentous Fungi ; Approved standard-Second Edition,M38-A2. Clinical and Laboratory Standard Institute CLSI. $2008 ; 28(16)$.

24. Mowat E, Butcher J, Lang S, Williams C, Ramage G. Development of a simple model for studying the effects of antifungal agents on multicellular communities of Aspergillus fumigatus. J. Med. Microbiol. Sep 2007;56(Pt 9):1205-1212.

This article is protected by copyright. All rights reserved. 
25. Seidler MJ, Salvenmoser S, Muller FM. Aspergillus fumigatus forms biofilms with reduced antifungal drug susceptibility on bronchial epithelial cells. Antimicrob. Agents Chemother. Nov 2008;52(11):4130-4136.

26. Papini M, Piraccini BM, Difonzo E, Brunoro A. Epidemiology of onychomycosis in Italy: prevalence data and risk factor identification. Mycoses. 2015;58:659-664.

27. Souza LK, Fernandes OF, Passos XS, Costa CR, Lemos JA, Silva MR. Epidemiological and mycological data of onychomycosis in Goiania, Brazil. Mycoses. Jan 2010;53(1):68-71.

28. Ataides FS, Chaul MH, El Essal FE, et al. Antifungal susceptibility patterns of yeasts and filamentous fungi isolated from nail infection. J. Eur. Acad. Dermatol. Venereol. Dec 2012;26(12):1479-1485.

29. Carrillo-Munoz AJ, Giusiano G, Guarro J, et al. In vitro activity of voriconazole against dermatophytes, Scopulariopsis brevicaulis and other opportunistic fungi as agents of onychomycosis. Int. J. Antimicrob. Agents. Aug 2007;30(2):157-161.

30. El Fekih N, Belghith I, Trabelsi S, Skhiri-Aounallah H, Khaled S, Fazaa B. Epidemiological and etiological study of foot mycosis in Tunisia. Actas Dermosifiliogr. 2012;103(6):520-524.

31. Succi IB, Bernardes-Engemann AR, Orofino-Costa R. Intermittent therapy with terbinafine and nail abrasion for dermatophyte toe onychomycosis: a pilot study. Mycoses. May 2013;56(3):327-332.

32. Piraccini BM, Sisti A, Tosti A. Long-term follow-up of toenail onychomycosis caused by dermatophytes after successful treatment with systemic antifungal agents. J. Am. Acad. Dermatol. Mar 2010;62(3):411-414.

33. Scher RK, Baran R. Onychomycosis in clinical practice: factors contributing to recurrence. Br. J. Dermatol. Sep 2003;149 Suppl 65:5-9.

34. Del Palacio A, Garau M, Gonzalez-Escalada A, Calvo MT. Trends in the treatment of dermatophytosis. 2000.

35. Shirwaikar AA, Thomas T, Shirwaikar A, Lobo R, Prabhu KS. Treatment of Onychomycosis: An Update. Indian J. Pharm. Sci. Nov-Dec 2008;70(6):710-714.

This article is protected by copyright. All rights reserved. 
36. Ozcan D, Seckin D, Demirbilek M. In vitro antifungal susceptibility of dermatophyte strains causing tinea pedis and onychomycosis in patients with non-insulin-dependent diabetes mellitus: a case-control study. J. Eur. Acad. Dermatol. Venereol. Dec 2010;24(12):1442-1446. 37. Sarifakioglu E, Seckin D, Demirbilek M, Can F. In vitro antifungal susceptibility patterns of dermatophyte strains causing tinea unguium. Clin. Exp. Dermatol. Nov 2007;32(6):675-679. 38. Jo Siu WJ, Tatsumi Y, Senda H, et al. Comparison of in vitro antifungal activities of efinaconazole and currently available antifungal agents against a variety of pathogenic fungi associated with onychomycosis. Antimicrob. Agents Chemother. Apr 2013;57(4):1610-1616.

39. Deng S, Zhang C, Seyedmousavi S, et al. Comparison of the in vitro activities of newer triazoles and established antifungal agents against Trichophyton rubrum. Antimicrob. Agents Chemother. Jul 2015;59(7):4312-4314.

40. Bueno JG, Martinez C, Zapata B, Sanclemente G, Gallego M, Mesa AC. In vitro activity of fluconazole, itraconazole, voriconazole and terbinafine against fungi causing onychomycosis. Clin. Exp. Dermatol. Aug 2010;35(6):658-663.

41. Barros ME, Santos Dde A, Hamdan JS. In vitro methods for antifungal susceptibility testing of Trichophyton spp. Mycological research. Nov 2006;110(Pt 11):1355-1360.

42. Bell-Syer SE, Khan SM, Torgerson DJ. Oral treatments for fungal infections of the skin of the foot. The Cochrane database of systematic reviews. Oct 17 2012;10:CD003584.

43. Gupta AK, Cooper EA. Update in antifungal therapy of dermatophytosis. Mycopathologia. Nov-Dec 2008;166(5-6):353-367.

44. Chadeganipour M, Nilipour S, Havaei A. In vitro evaluation of griseofulvin against clinical isolates of dermatophytes from Isfahan. Mycoses. Dec 2004;47(11-12):503-507.

45. Yenisehirli G, Tuncoglu E, Yenisehirli A, Bulut Y. In vitro activities of antifungal drugs against dermatophytes isolated in Tokat, Turkey. Int. J. Dermatol. Dec 2013;52(12):1557-1560.

46. Siqueira ER, Ferreira JC, Pedroso RS, Lavrador MA, Candido RC. Dermatophyte susceptibilities to antifungal azole agents tested in vitro by broth macro and microdilution methods. Rev. Inst. Med. Trop. Sao Paulo. Jan-Feb 2008;50(1):1-5.

47. Tan JS, Joseph WS. Common fungal infections of the feet in patients with diabetes mellitus. Drugs Aging. 2004;21(2):101-112.

48. Decroix J. Tinea pedis (mocassin-type) treated with itraconazole. Int. J. Dermatol. Feb 1995;34(2):122-124.

This article is protected by copyright. All rights reserved. 
49. Tosti A, Piraccini BM, Lorenzi S, Iorizzo M. Treatment of nondermatophyte mold and Candida onychomycosis. Dermatol. Clin. Jul 2003;21(3):491-497, vii.

50. Tosti A, Piraccini BM, Lorenzi S. Onychomycosis caused by nondermatophytic molds: clinical features and response to treatment of 59 cases. J. Am. Acad. Dermatol. Feb 2000;42(2 Pt 1):217-224.

51. Garcia-Effron G, Gomez-Lopez A, Mellado E, Monzon A, Rodriguez-Tudela JL, CuencaEstrella M. In vitro activity of terbinafine against medically important non-dermatophyte species of filamentous fungi. J. Antimicrob. Chemother. Jun 2004;53(6):1086-1089.

52. Baudraz-Rosselet F, Ruffieux C, Lurati M, Bontems O, Monod M. Onychomycosis insensitive to systemic terbinafine and azole treatments reveals non-dermatophyte moulds as infectious agents. Dermatology. 2010;220(2):164-168.

53. Tortorano AM, Richardson M, Roilides E, et al. ESCMID and ECMM joint guidelines on diagnosis and management of hyalohyphomycosis: Fusarium spp., Scedosporium spp. and others. Clin. Microbiol. Infect. Apr 2014;20 Suppl 3:27-46.

54. O'Donnell K, Sutton DA, Fothergill A, et al. Molecular phylogenetic diversity, multilocus haplotype nomenclature, and in vitro antifungal resistance within the Fusarium solani species complex. J. Clin. Microbiol. Aug 2008;46(8):2477-2490.

55. Al-Hatmi AM, van Diepeningen AD, Curfs-Breuker I, de Hoog GS, Meis JF. Specific antifungal susceptibility profiles of opportunists in the Fusarium fujikuroi complex. $J$. Antimicrob. Chemother. Apr 2015;70(4):1068-1071.

56. Ortoneda M, Capilla J, Javier Pastor F, Pujol I, Guarro J. In vitro interactions of licensed and novel antifungal drugs against Fusarium spp. Diagn. Microbiol. Infect. Dis. Jan 2004;48(1):69-71.

57. Machado Vila TV, Sousa Quintanilha N, Rozental S. Miltefosine is effective against Candida albicans and Fusarium oxysporum nail biofilms in vitro. J. Med. Microbiol. Nov 2015;64(11):1436-1449.

58. Gupta AK, Daigle D, Carviel JL. The role of biofilms in onychomycosis. J. Am. Acad. Dermatol. 2016;74(6):1241-1246.

59. Brilhante RSN, Correia EEM, Guedes GMdM, et al. Quantitative and structural analyses of the in vitro and ex vivo biofilm-forming ability of dermatophytes. J. Med. Microbiol. 2017;66(7):1045-1052.

This article is protected by copyright. All rights reserved. 
60. Høiby N, Bjarnsholt T, Moser C, et al. ESCMID* guideline for the diagnosis and treatment of biofilm infections 2014. Clin. Microbiol. Infect. 2015/05/01/ 2015;21:S1-S25.

\section{Figure legends}

Figure 1. Quantification of biofilm biomass formation after $72 \mathrm{~h}$ is represented by crystal violet absorbance at $570 \mathrm{~nm}$ (A) and safranin absorbance at $492 \mathrm{~nm}$ (B). Error bars represent standard deviation

Figure 2. Inhibition percentage of biofilm formation of dermatophyte and non-dermatophyte strains using different concentrations of econazole and terbinafine. Data are percentage of the mean of triplicates with respect to control. Error bars represent standard deviation.

Table1. Identification of dermatophyte and non-dermatophyte clinical strains used in this study

\begin{tabular}{ccccc}
\hline Strains & Sex & Clinical diagnosis & Clinical aspect & $\begin{array}{c}\text { Identification } \\
\text { (MALDI-TOF MS) }\end{array}$ \\
\hline T4 & F & Tinea pedis & PD & T.rubrum \\
T5 & M & Onychomycosis & DLSO & T.rubrum \\
T7 & M & Onychomycosis & DLSO & T.rubrum \\
T9 & M & Onychomycosis & PSO & T.rubrum \\
T11 & M & Onychomycosis & DLSO & T.rubrum \\
T12 & F & Onychomycosis & TDO & T.rubrum \\
T13 & F & Onychomycosis & DLSO & T.rubrum \\
T18 & F & Onychomycosis & DLSO & T.rubrum \\
T21 & F & Onychomycosis & DLSO & T.rubrum \\
T22 p & M & Tinea pedis & PH & T.rubrum \\
T23 & F & Onychomycosis & TDO & T.rubrum \\
T25 & F & Onychomycosis & DLSO & T.rubrum \\
T39 & M & Onychomycosis & TDO & T.rubrum \\
T40 & $M$ & Tinea pedis & PH & T.rubrum \\
T42 & M & Onychomycosis & PSO & T.rubrum \\
T46 & F & Onychomycosis & DLSO & T.rubrum \\
T52 & M & Onychomycosis & TDO & T.rubrum \\
T56 & M & Onychomycosis & DLSO & T.rubrum \\
T61 & F & Tinea pedis & ID & T.rubrum \\
T64 & M & Onychomycosis & PSO & T.rubrum \\
T66 & F & Onychomycosis & DLSO & T.rubrum \\
\hline
\end{tabular}

This article is protected by copyright. All rights reserved. 


\begin{tabular}{ccccc}
\hline T103 & M & Onychomycosis & DLSO & T.rubrum \\
T1 & F & Onychomycosis & DLSO & T.rubrum \\
T34I & F & Tinea pedis & ID & T.interdigitale \\
T44 & M & Onychomycosis & DLSO & T.interdigitale \\
T45 & F & Onychomycosis & TDO & T.interdigitale \\
T68 & F & Onychomycosis & TDO & T.interdigitale \\
M1 & F & Onychomycosis & TDO & F. oxysporum \\
M2 & F & Onychomycosis & DLSO & F. oxysporum \\
M3 & M & Onychomycosis & DLSO & S. brevicaulis \\
M6 & F & Onychomycosis & DLSO & S. brevicaulis \\
M12 & F & Onychomycosis & DLSO & S.brevicaulis \\
M5 & F & Onychomycosis & DLSO & A. terreus \\
M7 & F & Onychomycosis & DLSO & F. solani \\
M8 & F & Onychomycosis & DLSO & F. solani \\
T37 & F & Onychomycosis & DLSO & C. keratinophylum \\
M13 & M & Onychomycosis & DLSO & C. keratinophylum \\
\hline
\end{tabular}

NDMs: DLSO: Distal lateral subungual onychomycosis; ID: Interdigital; PD: Plantar

dishydrosis; PH: Plantar hyperkeratosis; PSO: Proximal subungual onychomycosis; TDO: Total dystrophic onychomycosis. A: Aspergillus; C: Chrysosporium; F: Fusarium; S: Scopulariopsis; T: Trichophyton.

This article is protected by copyright. All rights reserved. 
Table 2. Minimum inhibitory concentration (MIC) of five antifungal agents against dermatophyte and non-dermatophyte clinical strains

\begin{tabular}{|c|c|c|c|c|c|c|c|c|c|c|c|c|c|c|c|}
\hline \multirow{2}{*}{$\begin{array}{l}\text { Antifungal agents } \\
\text { Strains }\end{array}$} & \multicolumn{3}{|c|}{$\operatorname{FLC~MIC~}\left(\mu \mathrm{g} \mathrm{ml}^{-1}\right)$} & \multicolumn{3}{|c|}{ ECO MIC $\left(\mu \mathrm{g} \mathrm{ml}^{-1}\right)$} & \multicolumn{3}{|c|}{$\operatorname{ITC}$ MIC $\left(\mu \mathrm{g} \mathrm{ml}^{-1}\right)$} & \multicolumn{3}{|c|}{ TRB MIC $\left(\mu \mathrm{g} \mathrm{ml}^{-1}\right)$} & \multicolumn{3}{|c|}{ GSF MIC $\left(\mu \mathrm{g} \mathrm{ml}^{-1}\right)$} \\
\hline & $\mathrm{MIC}_{50}$ & $\mathrm{MIC}_{80}$ & $\mathrm{MIC}_{100}$ & $\mathrm{MIC}_{50}$ & $\mathrm{MIC}_{80}$ & MIC $_{100}$ & $\mathrm{MIC}_{50}$ & $\mathrm{MIC}_{80}$ & MIC $_{100}$ & $\mathrm{MIC}_{50}$ & $\mathrm{MIC}_{80}$ & MIC $_{100}$ & $\mathrm{MIC}_{50}$ & $\mathrm{MIC}_{80}$ & $\mathrm{MIC}_{100}$ \\
\hline \multicolumn{16}{|l|}{$\begin{array}{l}\text { Dermatophytes } \\
(\mathrm{n}=26)\end{array}$} \\
\hline \multicolumn{16}{|l|}{$\begin{array}{l}\text { Trichophyton } \\
\text { rubrum }(\mathrm{n}=21)\end{array}$} \\
\hline $\mathbf{T 4}$ & 32 & 64 & $>64$ & $<0.125$ & $<0.125$ & $<0.125$ & ND & 0.25 & 0.5 & $<0.031$ & $<0.031$ & $<0.031$ & 0.5 & 1 & ND \\
\hline T5 & 4 & 16 & 64 & $<0.125$ & $<0.125$ & $<0.125$ & $<0.031$ & $<0.031$ & $<0.031$ & $<0.031$ & $<0.031$ & $<0.031$ & 0.5 & 2 & 4 \\
\hline T7 & 16 & 16 & $>64$ & $<0.125$ & $<0.125$ & $<0.125$ & $<0.031$ & $<0.031$ & $<0.031$ & $<0.031$ & $<0.031$ & $<0.031$ & 0.5 & 1 & ND \\
\hline T9 & 32 & 64 & $>64$ & $<0.125$ & $<0.125$ & $<0.125$ & $<0.031$ & $<0.031$ & $<0.031$ & $<0.031$ & $<0.031$ & $<0.031$ & 4 & 8 & $>16$ \\
\hline T11 & 1 & 1 & 16 & $<0.125$ & $<0.125$ & $<0.125$ & 0.062 & 0.062 & 0.5 & $<0.031$ & $<0.031$ & $<0.031$ & $>16$ & $>16$ & $>16$ \\
\hline T12 & 0.125 & 0.125 & 4 & $<0.125$ & $<0.125$ & $<0.125$ & $<0.031$ & $<0.031$ & $<0.031$ & $<0.031$ & $<0.031$ & $<0.031$ & 0.5 & 1 & 2 \\
\hline T13 & 8 & 16 & 32 & $<0.125$ & $<0.125$ & $<0.125$ & $<0.031$ & $<0.031$ & $<0.031$ & $<0.031$ & $<0.031$ & $<0.031$ & 1 & 1 & 2 \\
\hline T18 & 32 & 32 & 64 & $<0.125$ & $<0.125$ & $<0.125$ & 0.125 & 0.25 & 0.5 & $<0.031$ & $<0.031$ & $<0.031$ & 1 & 2 & 4 \\
\hline $\mathbf{T} 21$ & 64 & 64 & $>64$ & $<0.125$ & $<0.125$ & $<0.125$ & 16 & 16 & $>16$ & $<0.031$ & $<0.031$ & $<0.031$ & 0.5 & 1 & 2 \\
\hline T22P & 8 & 16 & 64 & $<0.125$ & $<0.125$ & $<0.125$ & 0.125 & 0.125 & 0.25 & $<0.031$ & $<0.031$ & $<0.031$ & 0.5 & 1 & 2 \\
\hline $\mathbf{T} 23$ & 0.5 & 1 & 2 & $<0.125$ & $<0.125$ & $<0.125$ & 0.031 & 0.062 & 0.062 & $<0.031$ & $<0.031$ & $<0.031$ & 1 & 2 & 4 \\
\hline T25 & 4 & 4 & 8 & $<0.125$ & $<0.125$ & $<0.125$ & 0.125 & 0.25 & 0.5 & $<0.031$ & $<0.031$ & $<0.031$ & 4 & 8 & 16 \\
\hline T39 & 4 & 8 & 32 & $<0.125$ & $<0.125$ & $<0.125$ & 0.125 & 0.25 & 0.5 & $<0.031$ & $<0.031$ & $<0.031$ & ND & ND & ND \\
\hline T40 & 16 & 64 & $>64$ & 32 & 64 & $>64$ & 0.25 & 0.25 & 0.5 & $<0.031$ & $<0.031$ & $<0.031$ & 0.5 & 1 & 2 \\
\hline
\end{tabular}

This article is protected by copyright. All rights reserved. 


$\begin{array}{lcccccccccccccccc}\text { T42 } & 8 & 32 & >64 & 16 & 32 & 64 & 0.125 & 0.25 & 0.5 & <0.031 & <0.031 & <0.031 & 0.5 & 1 & >16 \\ \text { T46 } & 16 & 16 & >64 & <0.125 & <0.125 & <0.125 & <0.031 & <0.031 & <0.031 & <0.031 & <0.031 & <0.031 & 0.5 & 1 & \text { ND } & \\ \text { T52 } & >64 & >64 & >64 & <0.125 & <0.125 & <0.125 & 0.125 & 0.125 & 0.5 & <0.031 & <0.031 & <0.031 & \text { ND } & \text { ND } & \text { ND } & \\ \text { T56 } & 2 & 2 & 64 & <0.125 & <0.125 & <0.125 & 0.065 & 0.065 & 0.065 & <0.031 & <0.031 & <0.031 & \text { ND } & \text { ND } & \text { ND } \\ \text { T61 } & >64 & >64 & >64 & <0.125 & <0.125 & <0.125 & 0.062 & 0.125 & 0.25 & <0.031 & <0.031 & <0.031 & 1 & 2 & 4 \\ \text { T64 } & 4 & 8 & 64 & <0.125 & <0.125 & <0.125 & 0.062 & 0.25 & 0.5 & <0.031 & <0.031 & <0.031 & \text { ND } & \text { ND } & \text { ND } \\ \text { T66 } & 0.125 & 0.125 & >64 & <0.125 & <0.125 & <0.125 & <0.031 & <0.031 & <0.031 & <0.031 & <0.031 & <0.031 & 1 & 2 & 4 & \\ \text { T103 } & 0.5 & 2 & 64 & <0.125 & <0.125 & <0.125 & 0.062 & 0.125 & 0.5 & <0.031 & <0.031 & <0.031 & \text { ND } & \text { ND } & \text { ND }\end{array}$

\section{Trichophyton}

interdigitale $(\mathbf{n}=5)$

\begin{tabular}{|c|c|c|c|c|c|c|c|c|c|c|c|c|c|c|c|}
\hline T1 & 64 & 64 & $>64$ & $<0.125$ & $<0.125$ & $<0.125$ & $<0.031$ & $<0.031$ & $<0.031$ & $<0.031$ & $<0.031$ & $<0.031$ & 0.5 & 1 & 2 \\
\hline T34I & 64 & $>64$ & $>64$ & $<0.125$ & $<0.125$ & $<0.125$ & 0.125 & 0.25 & 0.25 & $<0.031$ & $<0.031$ & $<0.031$ & 0.5 & 1 & 2 \\
\hline T44 & 0.5 & 0.5 & 1 & $<0.125$ & $<0.125$ & $<0.125$ & $<0.031$ & $<0.031$ & $<0.031$ & $<0.031$ & $<0.031$ & $<0.031$ & 0.5 & 1 & $>16$ \\
\hline T45 & 64 & 64 & $>64$ & $<0.125$ & $<0.125$ & $<0.125$ & 0.065 & 0.065 & 0.125 & $<0.031$ & $<0.031$ & $<0.031$ & 1 & 2 & 4 \\
\hline T68 & $>64$ & $>64$ & $>64$ & $<0.125$ & $<0.125$ & $<0.125$ & 0.125 & 0.25 & 0.5 & $<0.031$ & $<0.031$ & $<0.031$ & 1 & 2 & 4 \\
\hline \multicolumn{16}{|c|}{ Molds $(n=10)$} \\
\hline \multicolumn{16}{|c|}{$\begin{array}{l}\text { Fusarium } \\
\text { oxysporum }(n=2)\end{array}$} \\
\hline M1 & $>64$ & $>64$ & $>64$ & 1 & 2 & 4 & 32 & $>16$ & $>16$ & 1 & 2 & 4 & $>16$ & $>16$ & $>16$ \\
\hline M2 & $>64$ & $>64$ & $>64$ & 4 & 8 & 16 & $>16$ & $>16$ & $>16$ & 4 & 8 & 16 & $>16$ & $>16$ & $>16$ \\
\hline
\end{tabular}

This article is protected by copyright. All rights reserved. 


\begin{tabular}{|c|c|c|c|c|c|c|c|c|c|c|c|c|c|c|c|}
\hline \multicolumn{16}{|l|}{$\begin{array}{l}\text { Fusarium solani } \\
(n=2)\end{array}$} \\
\hline M7 & $>64$ & $>64$ & $>64$ & $>64$ & $>64$ & $>64$ & $>16$ & $>16$ & $>16$ & $>16$ & $>16$ & $>16$ & $>16$ & $>16$ & $>16$ \\
\hline M8 & $>64$ & $>64$ & $>64$ & 64 & $>64$ & $>64$ & $>16$ & $>16$ & $>16$ & $>16$ & $>16$ & $>16$ & ND & ND & ND \\
\hline \multicolumn{16}{|l|}{ Scopulariopsis } \\
\hline \multicolumn{16}{|l|}{ brevicaulis $(\mathrm{n}=3)$} \\
\hline M3 & $>64$ & $>64$ & $>64$ & 16 & $>64$ & $>64$ & $>16$ & $>16$ & $>16$ & 4 & 8 & 16 & $>16$ & $>16$ & $>16$ \\
\hline M6 & $>64$ & $>64$ & $>64$ & 8 & 16 & $>64$ & $>16$ & $>16$ & $>16$ & 1 & 2 & 8 & $>16$ & $>16$ & $>16$ \\
\hline M12 & $>64$ & $>64$ & $>64$ & 0.5 & 1 & 4 & $>16$ & $>16$ & $>16$ & 0.25 & 0.25 & 2 & $>16$ & $>16$ & $>16$ \\
\hline \multicolumn{16}{|l|}{ Aspergillus terreus } \\
\hline M5 & $>64$ & $>64$ & $>64$ & $<0.125$ & $<0.125$ & $<0.125$ & $<0.031$ & $<0.031$ & $<0.031$ & $<0.031$ & $<0.031$ & $<0.031$ & $>16$ & $>16$ & $>16$ \\
\hline \multicolumn{16}{|l|}{ Chrysosporium } \\
\hline \multicolumn{16}{|l|}{$\begin{array}{l}\text { keratinophylum } \\
(\mathrm{n}=2)\end{array}$} \\
\hline T37 & 8 & 8 & 16 & $<0.125$ & $<0.125$ & $<0.125$ & $<0.031$ & $<0.031$ & $<0.031$ & $<0.031$ & $<0.031$ & $<0.031$ & 2 & 4 & 8 \\
\hline M13 & 2 & 4 & 8 & $<0.125$ & $<0.125$ & $<0.125$ & $<0.031$ & $<0.031$ & $<0.031$ & $<0.031$ & $<0.031$ & $<0.031$ & 0.25 & 0.5 & 1 \\
\hline T. mentagrophytes & 64 & 64 & $>64$ & $<0.031$ & $<0.031$ & $<0.031$ & $>64$ & $>64$ & $>64$ & $<0.031$ & $<0.031$ & $<0.031$ & 1 & 2 & 4 \\
\hline \multicolumn{16}{|l|}{ DSM 4870} \\
\hline $\begin{array}{l}\text { A. terreus DSM } \\
1958\end{array}$ & $>64$ & $>64$ & $>64$ & $<0.031$ & $<0.031$ & $<0.031$ & 0.065 & 0.065 & 0.065 & $<0.031$ & $<0.031$ & $<0.031$ & $>16$ & $>16$ & $>16$ \\
\hline
\end{tabular}

This article is protected by copyright. All rights reserved. 
FLC: fluconazole; ECO: econazole; ITC: itraconazole; TRB: terbinafine; GSF: griseofulvin; MIC $_{50}$ : the lowest concentration that caused $\geq 50 \%$ growth inhibition; $\mathrm{MIC}_{80}$ : the lowest concentration that caused $80 \%$ growth inhibition; MIC $_{100}$ :the lowest drug concentration that inhibited $100 \%$ of growth.

This article is protected by copyright. All rights reserved. 

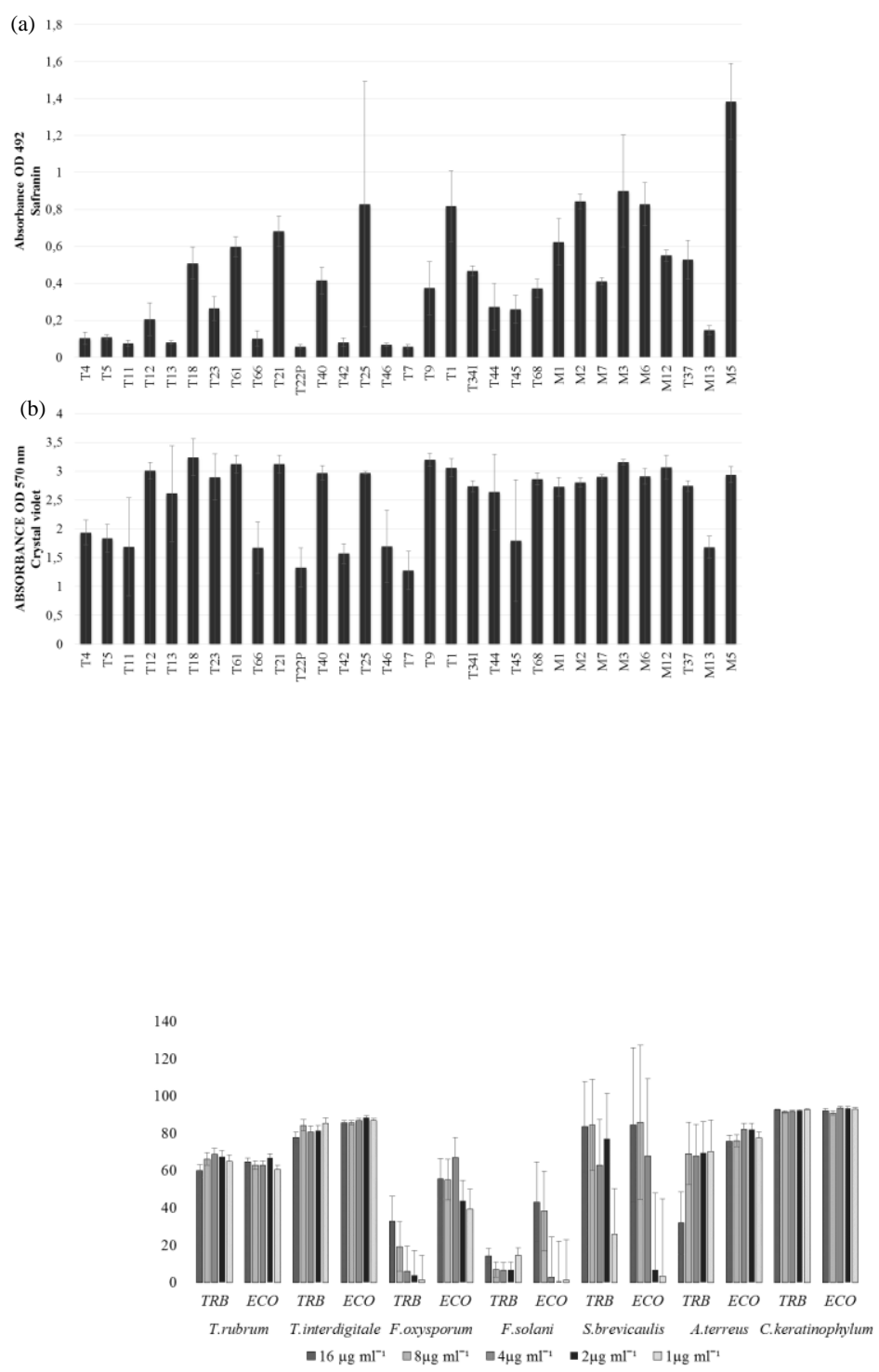

This article is protected by copyright. All rights reserved. 